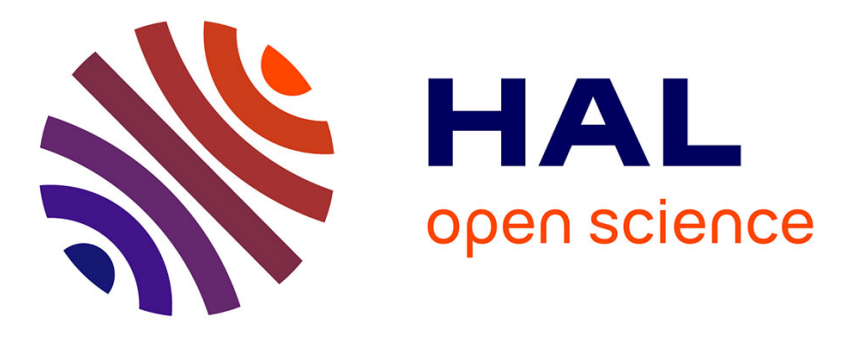

\title{
Estimation of charge neutralized by negative cloud-to-ground flashes in Catalonia thunderstorms
}

Joan Montanya, Serge Soula, Martin Murphy, Víctor March, Daniel

Aranguren, Glòria Solà, David Romero

\section{- To cite this version:}

Joan Montanya, Serge Soula, Martin Murphy, Víctor March, Daniel Aranguren, et al.. Estimation of charge neutralized by negative cloud-to-ground flashes in Catalonia thunderstorms. Journal of Electrostatics, 2009, 67, pp.513-517. 10.1016/j.elstat.2009.01.030 . hal-00441190

\author{
HAL Id: hal-00441190 \\ https://hal.science/hal-00441190
}

Submitted on 12 Jan 2022

HAL is a multi-disciplinary open access archive for the deposit and dissemination of scientific research documents, whether they are published or not. The documents may come from teaching and research institutions in France or abroad, or from public or private research centers.
L'archive ouverte pluridisciplinaire HAL, est destinée au dépôt et à la diffusion de documents scientifiques de niveau recherche, publiés ou non, émanant des établissements d'enseignement et de recherche français ou étrangers, des laboratoires publics ou privés.

\section{(ㄷ)(1) $\$$}

Distributed under a Creative Commons Attribution - NonCommerciall 4.0 International 


\title{
Estimation of charge neutralized by negative cloud-to-ground flashes in Catalonia thunderstorms
}

\author{
Joan Montanyà ${ }^{\mathrm{a}, *}$, Serge Soula ${ }^{\mathrm{b}}$, Martin Murphy ${ }^{\mathrm{c}}$, Víctor March ${ }^{\mathrm{a}}$, Daniel Aranguren ${ }^{\mathrm{a}, \mathrm{d}}$, Glòria Solà ${ }^{\mathrm{a}}$, \\ David Romero ${ }^{\mathrm{a}}$

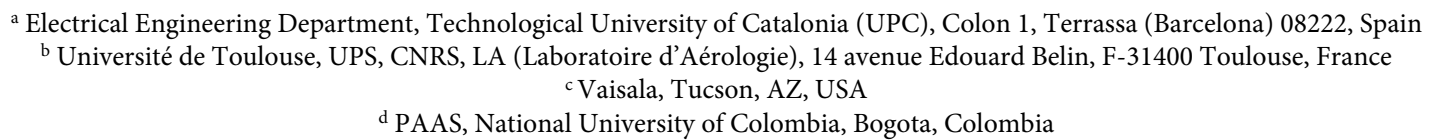

\begin{abstract}
Charges neutralized by lightning flashes have been usually located and inferred from the quasi-static changes in the vertical component of electric field $(\Delta E)$ obtained from multiple synchronized measurement stations. In this paper, the charges neutralized by negative cloud-to-ground $(-\mathrm{CG})$ lightning flashes are located and inferred using single station electric field measurements in combination with total lightning (cloud-to-ground and intra-cloud) data from lightning detection networks in the north-eastern region of Spain. The altitude of the negative charge region in 8 thunderstorms examined here was in the range of 5.8-7.2 km as inferred from temperature soundings. Charge locations are assumed to be in the region where the VHF (Very High Frequency) sources associated with the discharge are located. The quantity of charge neutralized is calculated using a point charge model and the measured vertical component of electric field $(\Delta E)$ associated with each flash. The results are compared with those previously obtained from measurements carried out in the NASA Kennedy Space Center (KSC) in Florida. The analysis of $260-$ CG flashes from eight thunderstorms reveals a median charge value of $-9.7 \mathrm{C}$ with $95 \%$ of the values ranging between $-4.5 \mathrm{C}$ and $-45 \mathrm{C}$.
\end{abstract}

\section{Introduction}

Jacobson and Krider in [1], Livingston and Krider in [2], Maier and Krider in [3], Koshak and Krider in [4,5], and Murphy et al. in [6], among many others, have analyzed the abrupt quasi-static electric field changes $(\Delta E)$ produced by lightning recorded at multiple distant synchronized stations. These measurements were performed using a field mill network at the NASA Kennedy Space Center (KSC). In these studies, the authors estimated and located the total charge $(\Delta Q)$ related to lightning flashes, obtaining good fits using a spherically-symmetric simple point charge model (or $\mathrm{Q}$ model). These studies revealed that the charges neutralized by negative cloud-to-ground ( $-\mathrm{CG}$ ) flashes ranged from $-4.5 \mathrm{C}$ to $-49 \mathrm{C}$ and were located at altitudes of 7.7 to $8.6 \mathrm{~km}$. Further, these studies showed that the altitude of the negative charge region remained practically constant for several storms and seemed to reside between the $-10^{\circ} \mathrm{C}$ and $-20^{\circ} \mathrm{C}$ isotherms. Krehbiel et al.

\footnotetext{
* Corresponding author. Tel.: +34 66979 3316; fax: +34 937398236

E-mail address: montanya@ee.upc.edu (J. Montanyà).
}

in [7] and Krehbiel in [8] also found constant altitudes for the negative charge region. Later, Stolzenburg et al. in [9-11] studied the electrical structure in thunderstorm convective regions by means of electric field soundings. For all soundings in New Mexico storms, they found the center of the main negative charge region at an average height of $6.9 \mathrm{~km}$ and at an average temperature of $-16{ }^{\circ} \mathrm{C}$. However, in supercells and mesoscale convective systems (MCS) the main negative charge region altitude showed more variability.

During summer 2003, an electric field measurement campaign was carried out in Catalonia (CAT) in the north-eastern region of Spain using a portable measurement station (Fig. 1). During the campaign, lightning-caused electric field changes were measured simultaneously using a single field mill and a flat-plate antenna beneath and near eight thunderstorms. Besides field measurements, total lightning (cloud-to-ground and intra-cloud) data were obtained from the two lightning detection networks operating in the region. Altitude temperature profiles obtained from soundings were used for computing the amount and the altitude of the charge neutralized in 260 cases of -CG flashes. 


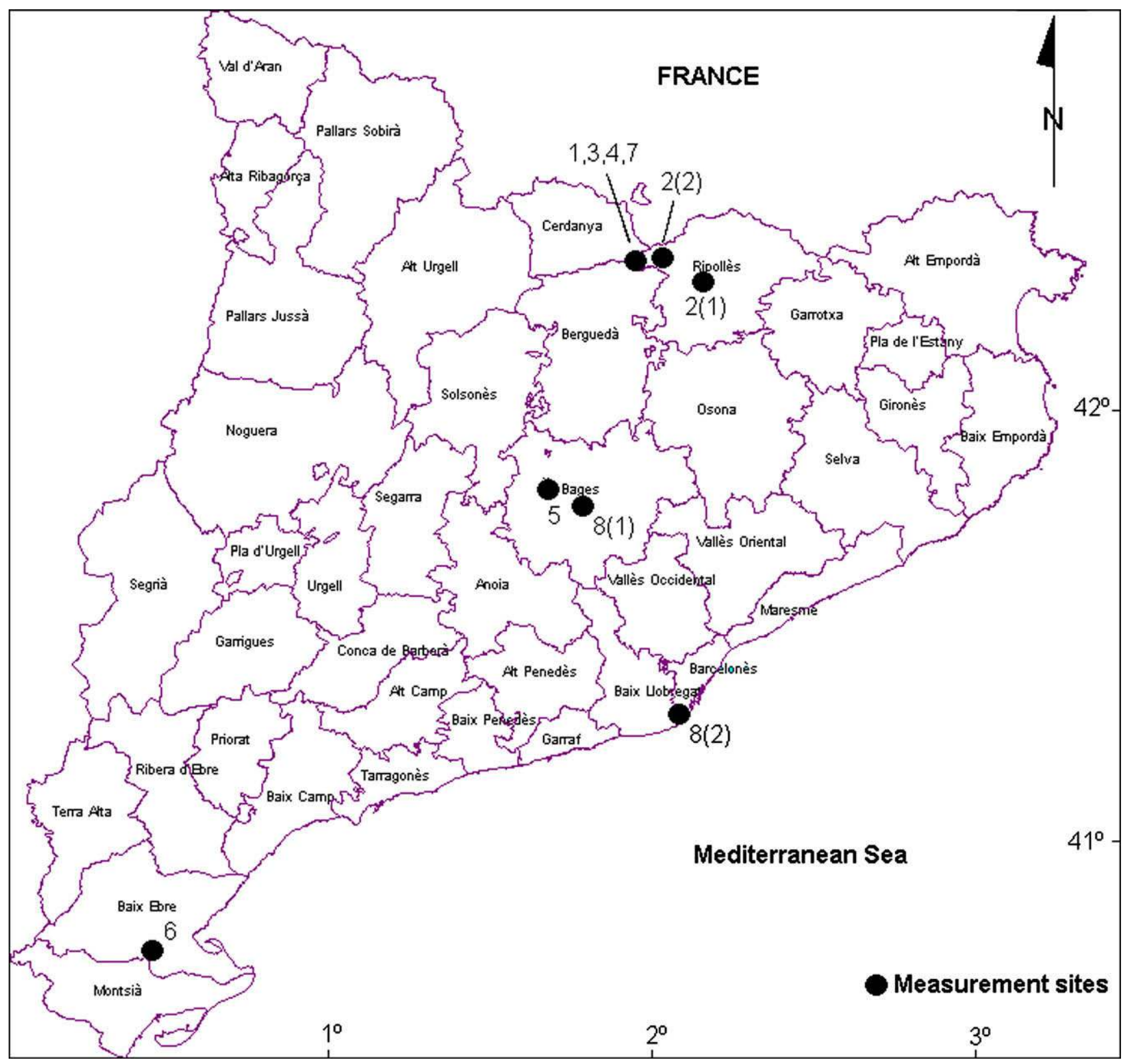

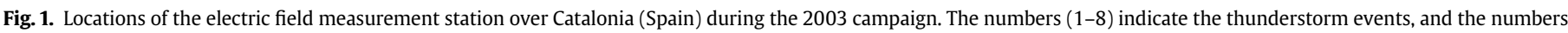
in brackets indicate different periods of the storm.

\section{Measurement systems and data}

According to Rivas Soriano et al. in [12], Catalonia is one of the most active regions for thunderstorms in Spain with a CG flash density up to 2.1 flash $\mathrm{km}^{-2}$ year $^{-1}$ in some areas. In order to enhance the chance of data collection, portable measurement equipment similar to that employed by Rust in [13] was used. Fig. 2 shows a picture of the portable measurement station.

\subsection{Portable electric field measurement station}

The electrostatic field was measured by a field mill and digitized at a rate of four samples per second. Additionally, electric field changes related to lightning flashes were measured by a slow flatplate antenna with an integration time-constant of $300 \mathrm{~ms}$. The signal from the flat antenna was digitized at a rate of $500 \mathrm{kHz}$ with $1 \mathrm{~s}$ record length. The electrostatic field and the field changes measured by the flat-plate antenna were time-synchronized by a time reference provided by a GPS. Examples of electrostatic field during a thunderstorm and field changes due to a particular lightning flash are presented in Fig. 3. For the calibration of the field mill, a second field mill was used as a reference. This field mill was vertically oriented and flush with the ground surface. The calibration was performed by comparison between both field mill measurements. In addition, the field changes obtained by the flat antenna were compared to those measured with the field mill and used to improve the calibration of the field mill. More details of the calibration are found in $[14,15]$.

\subsection{Lightning locating systems and total lightning data}

The north-eastern region of Spain is well covered by several lightning detection networks. The Spanish Lightning Detection Network (SLDN) provided the CG lightning flash characteristics 


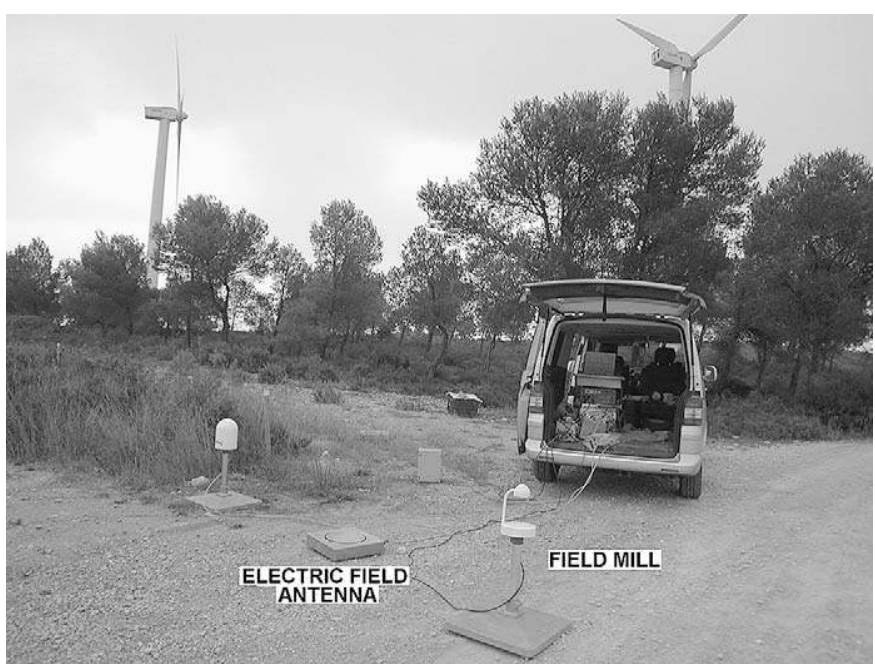

Fig. 2. Picture of the electric field measurement station employed during the campaign in 2003.

(time, location, polarity, multiplicity and peak current of the strokes) for this study. The SLDN consists of fifteen low-frequency (LF) sensors distributed over the Iberian Peninsula with combined magnetic-direction-finding and time-of-arrival (MDF/TOA) techniques [12]. These sensors are of the same type as those used by several networks like the National Lightning Detection Network (NLDN) in US [16,17]. The SLDN has been evaluated and calibrated several times using the same procedures applied to the NLDN $[18,19]$. The expected flash-detection efficiency and the average location accuracy are $90 \%$ and $0.5 \mathrm{~km}$, respectively [12,18].

Very High Frequency (VHF) sources associated with the total lightning activity were obtained from the Catalan Lightning Location Network (XDDE) operated by the Meteorological Service of Catalonia (SMC). During the summer of 2003, the XDDE was composed of three VHF interferometers such as that described in [20]. This network was limited to 100 detections per second providing 2D location of the VHF sources. The XDDE has been experimentally evaluated several times by means of electromagnetic field measurements and video recordings, resulting in a flashdetection efficiency of 93\% with an average VHF source location accuracy of $0.5 \mathrm{~km}$ [21]. The XDDE source grouping criteria are established so that two successive VHF sources are associated in the same flash if spatial and temporal intervals between them are lower than $7 \mathrm{~km}$ and $300 \mathrm{~ms}$, respectively.

\section{Model description}

During a thunderstorm, the electrostatic field experiences abrupt changes $(\Delta E)$ due to the charge neutralized by each lightning flash. The case of -CG flashes could be idealized as a simple decrease in the negative charge in the cloud, in which case a simple $\mathrm{Q}$ model is used to describe the charge $(\Delta Q)$ involved in each -CG event. This model has been largely employed by different authors, such as Jacobson and Krider in [1], Maier and Krider in [3], Koshak and Krider in [4] and Murphy et al. in [6], among many others. The equation in (1) describes the change of the vertical component of the electric field $\Delta E_{i}$ at ground level due to a variation of a single spherically-symmetric point charge, $\Delta Q_{i}$, in flash $i$, over a perfectly conducting ground plane.

$$
\Delta E_{i}=\frac{-2 \Delta Q_{i} z_{i}}{4 \pi \varepsilon_{o}\left[\left(x_{i}-x\right)^{2}+\left(y_{i}-y\right)^{2}+z_{i}^{2}\right]^{3 / 2}}
$$

where $\varepsilon_{0}$ is the permittivity of free space. The point charge is located at coordinates $\left(x_{i}, y_{i}, z_{i}\right)$ while the electric field measurement location is at $(x, y)$. The corresponding horizontal location $\left(x_{i}\right.$, $y_{i}$ ) is taken from the center of the total lightning locations obtained by the XDDE and SLDN related to a flash. Only those -CG flashes for which all the VHF sources were located within a horizontal radius of $1.5 \mathrm{~km}$ were included in the analysis. For these selected flashes, we assume that the negative charge region is located directly above the stroke location. The negative charge altitude $z_{i}$, is inferred from the altitude of the $-15{ }^{\circ} \mathrm{C}$ isotherm taken from the nearest temperature sounding and it is assumed constant during the storm. For the eight storms analyzed, the altitude corresponding to the $-15^{\circ} \mathrm{C}$ isotherm ranged from 5.8 to $7.2 \mathrm{~km}$.

\section{Results}

\subsection{Electric field changes versus horizontal distance}

The eight analyzed summer thunderstorms produced an average of 138 -CG flashes per storm with a maximum of 338 -CG flashes in one of these storms. The average multiplicity for -CG
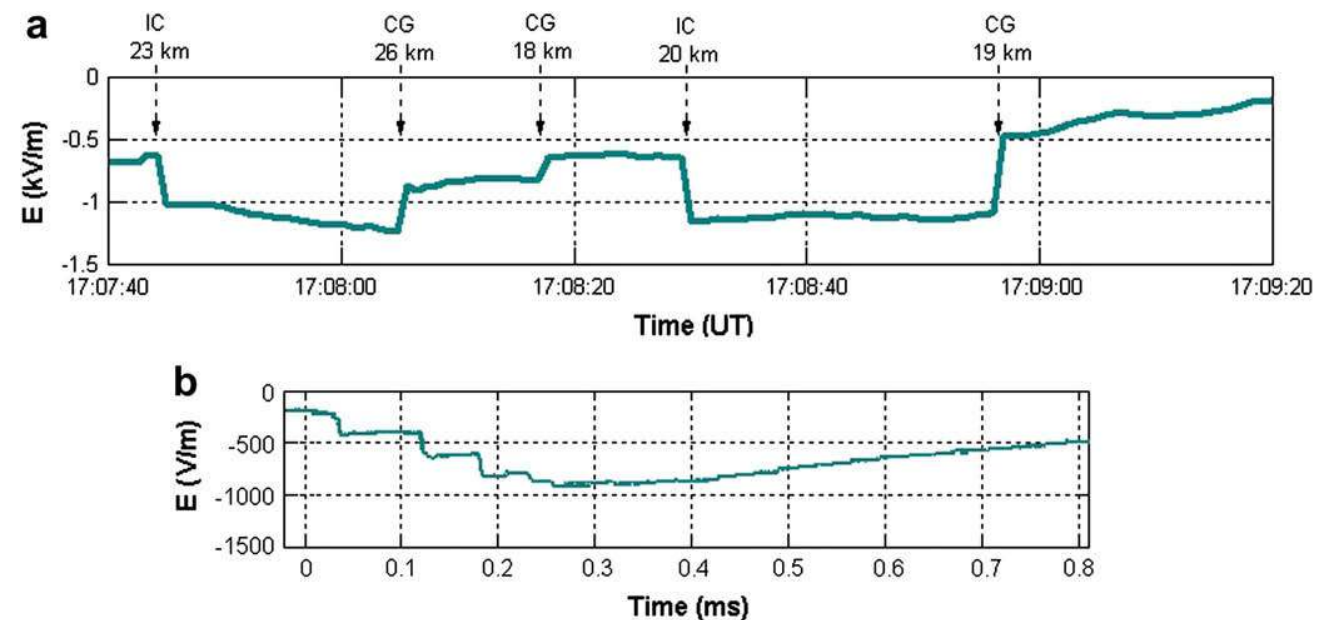

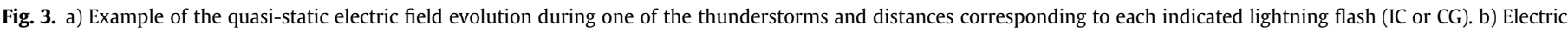
field changes measured by the flat-plate antenna due to the 17:08:56.6 (UT) flash. 
flashes was 1.9. The electric field changes due to 260 -CG flashes are shown as cross symbols in Fig. 4 versus the horizontal distance between the measurement station and the -CG flash location. Probably, one of the most studied types of storms by means of electric field changes are those that occur in Florida. In order to study if the electric field changes measured in CAT are similar to those measured in KSC, a linear model is used. Each data set (CAT and KSC) was fitted with a linear regression model. Since a linear regression model is a stochastic model, the relationship between endogenous variables ( $\Delta E$ in our case) and explicative variables ( $d$ in our case) should be linear. A Kolmogorov-Smirnov [22] normality test denoted a non-normal behaviour of the electric field changes in both distributions indicating log-normal distributions with a confidence interval of $80 \%$. A simple linearization was therefore introduced by taking a logarithmic transformation of each electric field change. With this simple transformation the correlation between electric field changes and horizontal distance was 0.78 and the coefficient of determination was 0.60 . The first order linear model obtained is defined in (2).

$\log \left|\Delta E_{i}(d)\right|=\beta_{0}+\beta_{1} d$

where $d$ is the horizontal distance in meters between the -CG stroke and the measurement location; $\beta_{0}$ and $\beta_{1}$ are the coefficients of the independent and the first order terms, respectively. The same procedure was applied to 68 electric field changes and horizontal locations obtained during some events of summers of 1984, 1985 and 1987 at KSC (Florida). After the transformation, the correlation between electric field changes and horizontal distance was 0.83 and the coefficient of determination was 0.7 . Table 1 describes the coefficients of both linear regression models obtained. The coefficients obtained in both models are close, indicating similar conditions of the charges related to -CG flashes in both locations. Fig. 4 displays both prediction models on a logarithmic scale. The graph shows that the electric field changes in Florida thunderstorms tend to be higher than changes observed in Catalonian thunderstorms. Nevertheless the maximum electric field change difference is $15 \%$.

\subsection{Comparison of charge and altitudes}

Larger electric field changes observed in KSC could be caused by differences in amounts of neutralized charge and their typical charge altitudes. To investigate the differences between the prediction models obtained in the last section (Fig. 4), an optimization problem [23] is formulated. In order to find a suitable
Table 1

Coefficients of prediction models for CAT and KSC.

\begin{tabular}{lll}
\hline & $\beta_{0}$ & $\beta_{1}$ \\
\hline CAT & 7.33 & -0.115 \\
KSC & 7.28 & -0.093 \\
\hline
\end{tabular}

objective function, we assume that there is much more variability between the two locations in the altitude of charge regions than there is in the typical amount of charge transferred by lightning. This assumption is consistent with suggestions made by Murphy et al. in [24] and with the results of Section 4.3. According to this, a simple objective function can be formulated in terms of finding the charge altitudes that minimize the charge difference for each distance.

$\min \left\{\left|\Delta Q_{\mathrm{KSC}}\left(\Delta E_{\mathrm{KSC}}(d), H_{\mathrm{KSC}}\right)-\Delta Q_{\mathrm{CAT}}\left(\Delta E_{\mathrm{CAT}}(d), H_{\mathrm{CAT}}\right)\right|\right\}$

Function in (3) expresses the charge difference between the two datasets (CAT and KSC) as a function of electric field change $\left(\Delta E_{\mathrm{KSC}}(d)\right.$ and $\left.\Delta E_{\mathrm{CAT}}(d)\right)$ and the charge altitudes $\left(H_{\mathrm{KSC}}\right.$ and $\left.H_{\mathrm{CAT}}\right)$ and finds the point charge altitudes $\left(H_{\mathrm{KSC}}\right.$ and $\left.H_{\mathrm{CAT}}\right)$, for which the charge change difference between the two datasets in all horizontal distances is a minimum. The resulting minimum charge change difference over all distances $(d)$ is $1.5 \mathrm{C}$ in average and the corresponding altitudes for Catalonia and KSC are $6.7 \mathrm{~km}$ and $8.3 \mathrm{~km}$, respectively. In the referenced works dealing with the electrical structure of Florida thunderstorms at KSC, the average altitude for the charges corresponding to -CG flashes was $8 \mathrm{~km}$, which is consistent with the $8.3 \mathrm{~km}$ obtained here. On the other hand, the mean $-15^{\circ} \mathrm{C}$ isotherm altitude of the eight thunderstorms measured in CAT during summer 2003 was $6.5 \mathrm{~km}$. The consistency of the altitudes of the charges not only validates the model employed in each region, but also denotes significant accuracy in the methodology employed in CAT with a single electrostatic field measurement and total lightning.

\subsection{The charge deposited by negative CG flashes}

The total charge related to every single flash is obtained by computing $\Delta Q$ in (1) for each of the $260-C G$ flashes. Fig. 5 shows the distribution of the total charge deposited by the -CG flashes. The values obtained range from -4.5 to $-45 \mathrm{C}$ for $95 \%$ of the flashes. This result is consistent with Maier and Krider in [3], who found a range from $-5 \mathrm{C}$ to $-33 \mathrm{C}$, Koshak and Krider in [4], who

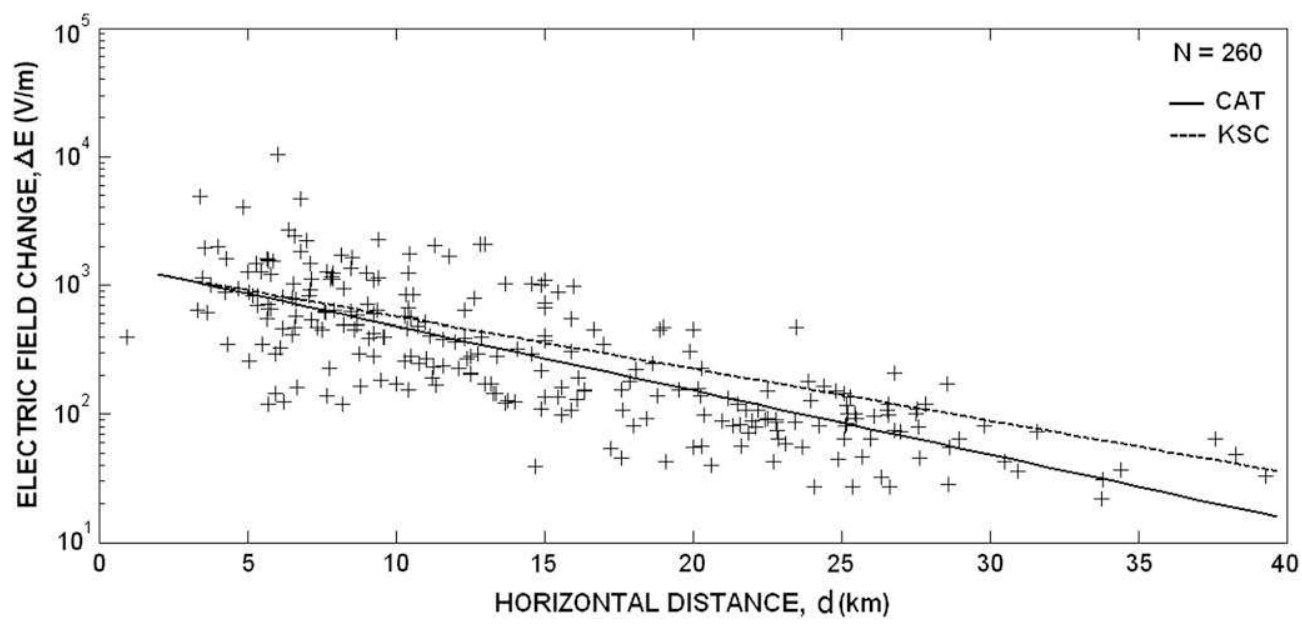

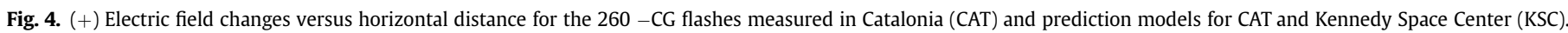




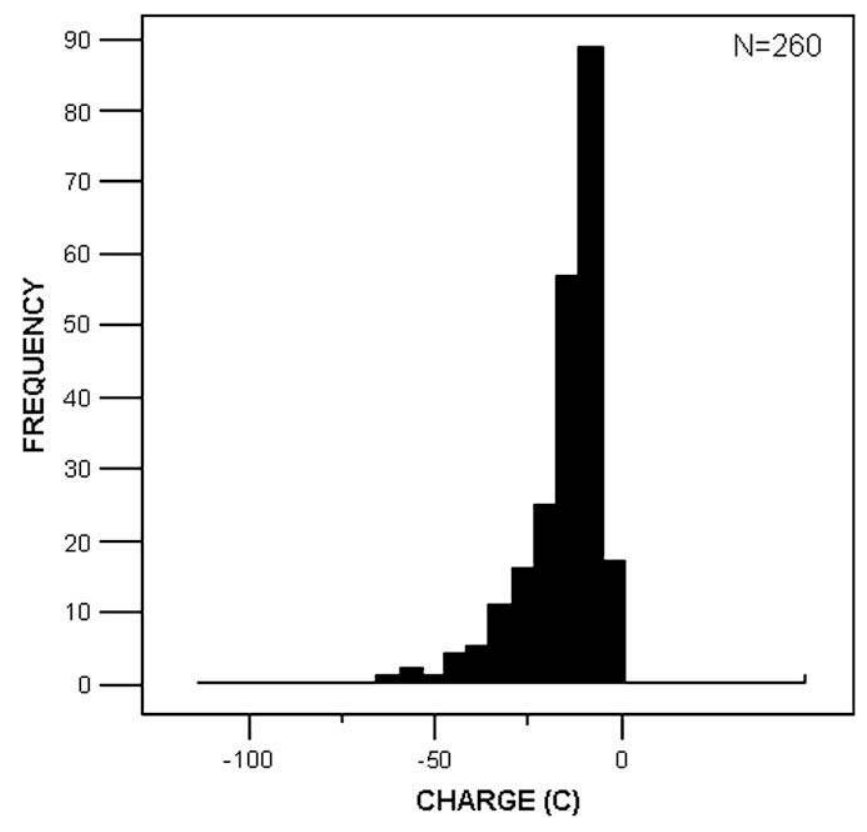

Fig. 5. Frequency distribution of the total charge amounts neutralized by the $-\mathrm{CG}$ flashes of Catalonian thunderstorms $(\mathrm{N}=260)$.

found a range from $-7 \mathrm{C}$ to $-49 \mathrm{C}$, and Krider in [25], who found a range from $-9 \mathrm{C}$ to $-48.4 \mathrm{C}$. Statistically, the distribution obtained is best fitted by a log-normal probability density function $p(\Delta Q)$.

$\left.p\left(\Delta Q_{i}\right)=\frac{1}{\sqrt{2 \pi} \Delta Q_{i} \widehat{\sigma}_{\ln }} \exp \left[-\frac{1}{2} \frac{\ln \left(\Delta Q_{i}\right)-\ln (\widehat{\mu})}{\widehat{\sigma}_{\ln }}\right)^{2}\right]$

where $\widehat{\mu}$ and $\widehat{\sigma}_{\ln }$ are the median values of $\Delta Q_{i}$ and the standard deviation of $\ln \left(\Delta Q_{i}\right)$, respectively. A median value of $-9.7 \mathrm{C}$ is obtained with a standard deviation of $0.82 \mathrm{C}$. The confidence interval is $90 \%$. These results are also consistent with measurements carried out at instrumented towers by Berger [26], who reported a median value of $-7.5 \mathrm{C}$ and a standard deviation of $1.02 \mathrm{C}$ for the charge of $-\mathrm{CG}$ flashes.

\section{Conclusion}

The electric field changes measured at a single site, together with total lightning locations given by the lightning detection networks that operate in Catalonia, allowed us to infer the total charge deposited by -CG flashes. Electric field changes versus horizontal distance from the -CG strokes in CAT have been compared with the same distributions measured previously at KSC (Florida). Assuming a single point charge model, the comparison denoted an average charge difference between KSC and CAT of $1.5 \mathrm{C}$ with altitudes of $8.3 \mathrm{~km}$ and $6.7 \mathrm{~km}$, respectively. These heights are consistent with those estimated experimentally in KSC and correspond to the average $-15^{\circ} \mathrm{C}$ isotherms in CAT for the studied storm episodes. On the other hand, the total neutralized charge values related to - CG flashes in the eight thunderstorms in CAT ranged from -4.5 to $-45 \mathrm{C}$. These results are also consistent with those obtained at KSC, which ranged from $-5 \mathrm{C}$ to $-49 \mathrm{C}$. Thus, the $-\mathrm{CC}$ flashes that occurred in the studied storm episodes in CAT presented similar charges at lower altitudes compared to KSC summer storms. The charge amount distribution of the analyzed -CG flashes has been defined by a log-normal probability density function with a median value of $-9.7 \mathrm{C}$ and a logarithm standard deviation of $0.82 \mathrm{C}$. These values are comparable to previously published results on direct measurements at instrumented towers struck by lightning.

The results obtained suggest that the two main assumptions in this work (charge altitude adopted from $-15^{\circ} \mathrm{C}$ isotherm height and charge location adopted from the total lightning locations) are reasonable and the methodology presented in this paper based on single-site electrostatic field measurement and total lightning offers a simple procedure to investigate charges in those regions where total lightning data are available.

\section{References}

[1] E.A. Jacobson, E.P. Krider, Electrostatic field changes produced by Florida lightning, J. Atmos. Sci. 33 (1976) 103-117.

[2] J.M. Livingston, E.P. Krider, Electric fields produced by Florida thunderstorms, J. Geophys. Res. 83 (1978) 385-401.

[3] L.M. Maier, E.P. Krider, The charges that are deposited by cloud-to-ground lightning in Florida, J. Geophys. Res. 91 (1986) 13275-13289.

[4] W.J. Koshak, E.P. Krider, Analysis of lightning field changes during active Florida thunderstorms, J. Geophys. Res. 94 (1989) 1165-1186.

[5] W.J. Koshak, E.P. Krider, A linear method for analyzing lightning field changes, J. Atmos. Sci. 51 (1994) 473-487.

[6] M.J. Murphy, E.P. Krider, M.W. Maier, Lightning charge analyses in small convection and precipitation electrification (CaPE) experiment storms, J. Geophys. Res. 101 (1996) 29615-29626.

[7] P.K. Krehbiel, M. Brook, R.A. McCrory, An analysis of the charge structure of lightning discharges to ground, J. Geophys. Res. 84 (1979) 2432-2456.

[8] P.K. Krehbiel, The Electrical Structure of Thunderstorms. The Earth's Electrical Environment, National Academy Press, 1986, 90-113.

[9] M. Stolzenburg, W.D. Rust, B.F. Smull, T.C. Marshall, Electrical structure in thunderstorm convective regions 1 . Mesoscale convective systems, J. Geophys. Res. 103 (1998) 14059-14078.

[10] M. Stolzenburg, W.D. Rust, T.C. Marshall, Electrical structure in thunderstorm convective regions 2. Isolated storms, J. Geophys. Res. 103 (1998) 1407914096.

[11] M. Stolzenburg, W.D. Rust, T.C. Marshall, Electrical structure in thunderstorm convective regions 3. Synthesis, J. Geophys. Res. 103 (1998) 14097-14108.

[12] L. Rivas Soriano, F. de Pablo, C. Tomas, Ten-year study of cloud-to-ground lightning activity in the Iberian Peninsula, J. Atmos. Sol. Terr. Phys. 67 (2005) 1632-1639.

[13] W.D. Rust, Utilization of a mobile laboratory for storm electricity measurements, J. Geophys. Res. 94 (1989) 13305-13311.

[14] Montanyà, J, Estudio de la carga eléctrica asociada al rayo: caracterización de las tormentas en Cataluña, PhD dissertation, Technological University of Catalonia UPC, 2004.

[15] IEEE Std 1227-1990, IEEE Guide for the Measurement of DC Electric-Field Strength and Ion Related Quantities, IEEE Standard, 1990.

[16] K.L. Cummins, M.J. Murphy, E.A. Bardo, W.L. Hiscox, R.B. Pyle, A combined TOA/ MDF technology upgrade of the U.S. National Lightning Detection Network, J. Geophys. Res. 103D (1998) 9035-9044.

[17] R.E. Orville, Development of the National Lightning Detection Network, Bull. Am. Meteorol. Soc. 8 (2008) 180-190.

[18] F. Pérez, Cooperación entre las redes de rayos de España y Portugal, in: Proceedings of the 28th Jornadas Científicas de la Asociación Meteorológica Española, Badajoz, Spain, 2005.

[19] M.J. Murphy, A. Pifer, K.L. Cummins, P. Richard, J. Cramer, The 2002 upgrade of the U.S. NLDN, in: Proceedings of the 17th International Lightning Detection Conference, 2002, Tucson, US.

[20] P. Richard, J.Y. Lojou, Assessment of application of storm cell electrical activity monitoring to intense precipitation forecast, in: Proceedings of the 10th International Conference on Atmospheric Electricity, Osaka, Japan, 1996, pp. 284-287.

[21] J. Montanyà, N. Pineda, V. March, A. Illa, D. Romero, G. Solà, Experimental evaluation of the Catalan Lightning Detection Network, in: Proceedings of the 19th International Lightning Detection Conference, 2006, Tucson, USA.

[22] W.T. Eadie, D. Drijard, F.E. James, M. Roos, B. Sadoulet, Statistical Methods in Experimental Physics, North-Holland, Amsterdam, 1971, 269-271.

[23] J. Nocedal, J.S. Wright, Numerical Optimization, Springer, 2006.

[24] M.J. Murphy, R.L. Holle, N.W.S. Demetriades, Cloud-to-ground lightning warnings using total lightning Mapping and electric field mill observations, in: Third Conference on Meteorological Applications of Lightning Data, American Meteorological Society, 2008.

[25] E.P. Krider, Electric field changes and cloud electrical structure, J. Geophys. Res. 94 (1989) 13145-13149.

[26] K. Berger, R.B. Anderson, H. Kroninger, Parameters of lightning flashes, Electra 41 (1975) 23-37. 